that family information is not considered of much importance in the management of acute psychiatric admissions (Cottrell, 1989). However, it is to be hoped that the appearance of recent publications on aspects of parental psychiatric disorder may be an indication of changing attitudes and practice.

One practical reason for lack of awareness of patients' children is that they are generally 'invisible' to senior clinicians and managers who are rarely on wards at visiting times. This study found that children of patients are frequent visitors on some acute psychiatric wards despite very inadequate provision for them. Wider recognition of child visiting could lead to simple but imaginative adaptations such as rooms being set aside for family visits and the provision of some toys and games.

\section{References}

COTTRELL, D. (1989) Family therapy influences on general psychiatry. British Journal of Psychiatry, 130. 201-210.
EKDAHL, M. C.. RICE, E. P. \& SCHMIDT, M. (1962) Children of parents hospitalised for mental illness. American Journal of Public Health, 52, 428-435.

Gopfert, M.. Webster, J. \& SeEman, M. V. (eds) (1996) Parental Psychiatric Disorder. Cambridge: Cambridge University Press.

HATFIELD, B., WEBSTER, J. \& MOHAMED, H. (1997) Psychiatric emergencies: assessing parents of dependent children. Psychiatric Bulletin, 21, 19-22.

OATES, M. (1997) Patients as parents: the risk to children. British Journal of Psychiatry, 170 (suppl. 32). 22-27.

RUTTER, M. \& QUINTON. D. (1984) Parental psychlatric disorder: effects on children. Psychological Medicine. 14. 853-880.

Stormont, F. Craig, T., AKakan, Z., et al (1997) Concerns about the children of psychlatric inpatients: what parents say. Psychiatric Bulletin, 21, 495-497.

*Valerie Hawes, Specialist Registrar, Forensic Psychiatry Service, Box 175, Addenbrooke's Hospital, Hills Road, Cambridge CB2 290 and David Cottrell, Professor, Academic Unit of Child and Adolescent Mental Health, School of Medicine, University of Leeds, Leeds

*Correspondence

\title{
Reducing the time you and your patients wait
}

\author{
Kadiyali M. Srivatsa and Danny Allen
}

\begin{abstract}
Aims and methods in an attempt to reduce patient non-attendance at first appointments, consultant referrals were handled differentially over three years. From referral letters some patients were referred elsewhere, some sent appointments and some invited to make appointments.

Results There was a reduction in patients who did not attend an appointment and an increase in the proportion of patients, not referred elsewhere who were seen.

Clinical implications This system reduces consultant waiting time in clinics and the interval before a patient is seen.

Traditionally, patients referred to a psychiatrist are sent appointments; some do not attend. These 'empty slots' can waste a lot of time and significantly increase the waiting list, with
\end{abstract}

attendant problems of morbidity, hospital admission and potential contractual difficulties. One study in a community setting indicated a 'no-show' rate of between 26 and 50\% (Chen. 1991). Another study showed that there was an association with length of wait for an appointment, previous treatment, chief complaint and source of referral (Carpenter et al, 1981). A study by psychologists indicated that the nonattendance rate for subsequent appointments dropped once the initial appointment had been kept (Weighill et al, 1983). Various methods have been tried to reduce missed appointments, such as telephone reminders (Hochstadt \& Trybula, 1980; Carr, 1985) and completing behavioural check-lists (Deane, 1991) but with only limited success. Sparr et al (1993) found that patients with post-traumatic stress disorder and substance misuse were significantly 
more likely than others to miss appointments, while Errera et al (1965) in their study of preintake drop-out at a psychiatric clinic noted that the biggest group of non-attenders were people for whom the idea of seeing a psychiatrist had not emanated from themselves. Sometimes these were individuals whom family doctors found it difficult, for whatever reason. to continue to manage on their own and sometimes concern was expressed to the family doctor by social or legal agencies or relatives. Of these individuals, they found, two-thirds failed to attend appointments.

\section{The study}

The study extended over three years. It followed service changes which were deliberately introduced in two phases so as to test the new system out and to introduce new working methods to the administration gradually. In the initial (control) period, 1994-1995. virtually all patients referred to a consultant psychiatrist by general practitioners were sent appointments for an outpatient clinic, as had been the practice for many years.

In the interim period, 1995-1996, the referral letters were scrutinised and where referral to a general adult psychiatric clinic was thought to be inappropriate, the referrer was informed and advised about a more appropriate course of action. Patients with problems which were directed elsewhere included: people whose sole reason for referral was substance misuse, these were directed to a specialist service; patients where the referrer did not claim there was a mental health problem but where 'counselling' was sought, these were directed towards agencies in the community: and patients for whom specific therapies were requested or indicated by the referral letter, where direct onward referral was instituted (e.g. anxiety management in the day hospital or psychotherapy from the psychotherapy department).

In this interim period, two other groups of subjects were singled out for different treatment. The first was based on the work of Sparr et al (1993) and represented those referrals where the problem appeared, on the basis of the referral letter, to be related to alcohol or drug misuse. The second was based on the work of Errera et al (1965) and represented those referrals where there was clear evidence in the referral letter that the motivation came from someone other than the nominated patient. Both these groups were sent a letter inviting them to contact the departmental secretary within 14 days to arrange a convenient time and date for a consultation. If they failed to attend the family doctor was informed of this by letter.
In the final period, 1996-1997, all referrals were asked to contact the department to make an appointment as per the arrangement above. In this period the referral letters of non-responders were reviewed and general practitioners were informed if there had been no response. If the referral appeared to merit further action such as a domiciliary visit or a Mental Health Act assessment these were proposed by the consultant, otherwise a standard letter was sent.

During the period of the study, referral letters had been annotated according to the type of response. These were then analysed with regard to diagnostic data and checked against the record system in the department. Where records were unclear these were checked against the notes.

\section{Findings}

Three hundred and sixty-two referrals were initially included in the study representing all the consultant referrals in the period March 1994 to March 1997. The patients referred for consultation were grouped as Year 1 (March 1994-95), Year 2 (March 1995-96) and Year 3 (March 1996-1997).

In Year $1(n=107)$, one was referred directly to another agency making a total of 106 who were 'eligible to be seen'. All of these received appointments, $30(28 \%)$ did not attend them. Overall, $28 \%$ of people were not seen despite being offered contact and $28 \%$ were not seen for all reasons.

In Year $2(n=147), 22(15 \%)$ were referred directly to other agencies making a total of 125 patients who were 'eligible to be seen'. Of these $108(86 \%)$ patients received appointments and $17(14 \%)$ received invitations to contact the service. Seventeen (14\%) of the appointees did not attend and six (35\%) of the invitees did not make contact with the service. In total $18 \%$ of 'eligible to be seen' patients did not attend/make contact. All those who made appointments after being invited to telephone in attended their appointments. Overall, $16 \%$ of people were not seen despite being offered contact and $31 \%$ were not seen for all reasons.

In Year $3(n=108)$ two patients died - one had been sent an invitation. Twenty-one were referred directly to other agencies making a total of 85 who were 'eligible to be seen'. All of these received invitations to contact the service and 16 (19\%) did not do so. All those who made appointments after being invited to telephone in attended their appointments. Overall, $15 \%$ of people were not seen despite being offered contact and $34 \%$ (excluding the two deaths) were not seen for all reasons.

The decrease in the proportion of 'eligible to be seen' patients who did not attend arranged 
appointments in Year 3 (all sent invitations) compared with Year 1 (all sent appointments) is statistically significant $\left(\chi^{2}=24.0,1 \mathrm{df}, P<0.001\right)$.

The increase in the proportion of eligible to be seen' patients actually seen in Year 2 (some sent appointments, some sent invitations) compared with Year 1 (all sent appointments) is statistically significant $\left(\chi^{2}=4.114,1 \mathrm{df}, P<0.05\right)$ but less so when comparing Year 3 (when all were sent invitations $)$ with Year $1 \quad\left(\chi^{2}=2.666,1 \mathrm{df}\right.$, $0.1<P<0.25$ ).

\section{Comment}

Changes in service provision were originally undertaken because of concern about the amount of time spent in out-patients by the psychiatrist with no-one to see (i.e. a therapist centred reason). The study followed the two phases of this process which, as indicated, was based initially on considerations from the literature. There is no doubt that sending invitations to new referrals has dramatically improved this situation. However, the anxiety was always that the overall number of people seen would decrease as people might be less motivated to make contact by telephone than they are to turn up for an appointment.

It is interesting that, contrary to the findings of Ali \& McBride (1997) the number of people attending for assessment compared to those referred remained pretty constant at around $70 \%$ throughout the study period and that the overall 'not seen' rate was actually lower in those patients offered contact in Years 2 and 3. In Year 2 it is noteworthy that, despite the small sample, over a third of patients with putative substance misuse or poor motivation did not attend compared with only $14 \%$ of others.

The overall referral rates varied, with the first and final year being similar but a considerably larger number referred in the interim year. We have no explanation for this but it is important to understand that we were only looking at consultant referrals and team referrals run in parallel to this system. It would be an interesting, but separate, study to examine the relationship between the two systems.

An important variable is the number of people sent to other agencies on the basis of their referral letters. Because this change was introduced at the same time as the invitation letters and this group of people has not been followed up in this study it is not really possible to comment meaningfully on those people who were not seen throughout the study though it would be interesting to do so in future. However, whatever the outcome there are obvious theoretical advantages to referring patients onwards to the agency deemed most appropriate to their needs.
It is interesting to speculate why people might prefer being offered an invitation. Experience both during and after the study period indicates that negotiation takes place as to when they might be seen; it is possible that for those with marginal motivation this may make the difference between attending or not. The system is good at dealing with 'urgent cases' so patients can be seen sooner than they would otherwise be if they were to be sent an appointment in the post. Both from this view and from that of clinic organisation it is very good at 'filling holes': patients who ring in early can sometimes be offered an appointment the next day. More work is needed, however, to see whether patients are more likely to respond to an invitation than to an appointment.

The system is not perfect. Although the verbally made appointments are confirmed by letter, since the study period ended we have had several patients who have claimed not to have received it and used this as their reason not to attend a verbally agreed appointment - others have simply not shown up. However, these are the exceptions and in many cases such people have contacted us again to explain their absence and to request a further appointment.

The system has been explained to general practitioners. They do not seem to be aware of its provisions judging by the nature of their referral letters but, by the same token, there have not been any complaints - particularly when we have had to write to them telling them that their patient did not attend. No general practitioner has complained that we are not trying hard enough' to access patients. A theoretical issue would be whether all patients have access to a telephone. Certainly some have rung from public telephones but when non-attenders have been re-referred the issue of communication has never been raised though that of changed motivation is frequently cited.

There are some patients for whom this approach may not be appropriate, in particular those with language problems. Since the study period ended we have given certain patients appointments via the Asian Link Worker who can also bring them to the appointment. However, patients who are referred with what appears to be a psychotic illness can use this system appropriately as often motivation comes from carers who bring them. If they do not respond the system is set up so that letters are reviewed and an appropriate care plan is designed for the particular circumstances in consultation with the general practitioner.

Further work needs to be conducted to see if the changes which we observed are reproducible in other settings and also to identify exactly what factors lie behind the changes we observed. 


\section{References}

AU, I. M. \& MCBRIDE. A. (1997) Attendance rate in an alcohol problem clinic. Psychiatric Bulletin. 21, 343-345.

Carpenter. P. J.. Morrow, G. R., Del Gaudio, A. C., et al (1981) Who keeps the first outpatient appointment? American Joumal of Psychiatry, 138, 102-105.

CARR. V. C. (1985) Telephone prompting to reduce missed CMHT appointments. Hospital and Community Psychiatry, 36, 1217-1218.

Chen, A. (1991) Non-compliance in community psychiatry: A review of clinical interventions. Hospital and Community Psychiatry. 42. 282-287.

DEANE. F. P. (1991) Improving attendance at intake in children's outpatient services of a community mental health centre. Child Care. Health and Development, 17. 115-121.

ERrera, P.. DAVEnPORT, P. \& Decker. L. (1965) Pre-intake dropout in a psychiatric clinic. Mental Hygiene, 49. 588-563.
HochstaDT, N. J. \& TRYBULA, J. R. (1980) Reducing missed initial appointments in a community mental health center. Joumal of Community Psychology. 17. 303-311.

SPARR, L. F., MOFFITT, M. C. \& WARD, M. F. (1993) Missed psychiatric appointments: who returns and who stays away. American Journal of Psychiatry. 160, 801-805.

Weighil., V. E., HODGE, J. T. \& PECK. D. F. (1983) Keeping appointments with a clinical psychologist. British Journal of Clinical Psychology. 22. 143-144.

Kadiyali M. Srivatsa, Former Psychiatric Senior House Officer, and "Danny Allen, Consultant Psychiatrist, North Wycombe Community Mental Health Team, 1 Cedar Avenue, Hazlemere, High Wycombe, Buckinghamshire HP15 7DW

*Correspondence

\title{
Psychiatrists' views of evidence- based psychiatric practice
}

\author{
Stephen Carey and David J. Hall
}

\begin{abstract}
Aims and method To determine the attitudes of psychiatrists towards the practice of evidence-based medicine by use of a postal questionnaire. A survey was sent to Consultant Psychiatrists and to Higher Trainees in Psychiatry in the West of Scotland Region.

Results While older influences on decision-making such as tradition and deference still play a part almost all respondents consider the adoption of more effective care based on best available external evidence desirable; most think it attainable. The technology is generally available, but further training is desired to access the information and its critical analysis.

Clinical implications Educational activities should increasingly focus on skills for data search and critical analysis.
\end{abstract}

Evidence-based medicine is "the conscientious, explicit and judicious use of the current best evidence in making decisions about the care of individual patients" (Sackett et al, 1996). In its practice the clinician must define the clinical question to be answered, search for the evidence, appraise it and apply it (Geddes \& Harrison, 1997). It has been highlighted that evidencebased' decision-making may be subject to pre-existing beliefs and an unconscious filtering of even the best evidence (Anderson, 1997), and that a technology is required (Sheldon \& Gilbody. 1997). It has been suggested that new evidence is required (Lewis, 1997), with new clinicallyrelevant, randomised controlled trials. Nevertheless it has been suggested in one study that evidence was identified to support $53 \%$ of psychiatric interventions (Summers \& Kehoe. 1996) and a recent editorial has indicated the benefits of structuring journal clubs along evidence-based lines (Geddes, 1998). General practitioners have been shown mainly to welcome evidence-based medicine, and to adopt it in a substantial part of their clinical practice (McColl et al, 1998). Clinicians may, however, base decision-making instead on tradition. clinical intuition or deference to a senior colleague (Schmidt et al, 1996).

In the recent Scottish Office White Paper Designed to Care-Reviewing the National Health Service in Scotland, the Government is "promoting the adoption of more effective care based on evidence". In this study we sought the views of consultant psychiatrists and senior registrars (SR)/specialist registrars (SpR) in psychiatry, in the West of Scotland, concerning the practice of evidence-based psychiatry. 